\title{
CHARACTERIZATION OF SHEAR BOND STRESS FOR DESIGN OF COMPOSITE SLABS USING AN IMPROVED PARTIAL SHEAR CONNECTION METHOD
}

\author{
Redzuan ABDULLAH ${ }^{\mathrm{a}}$, Ahmad Beng Hong $\mathrm{KUEH}^{\mathrm{b}}$, Izni S. IBRAHIM ${ }^{\mathrm{a}}$, \\ W. Samuel EASTERLING ${ }^{\mathrm{c}}$ \\ ${ }^{a}$ Faculty of Civil Engineering, Universiti Teknologi Malaysia, \\ 81310 UTM Johor Bahru, Johor, Malaysia \\ ${ }^{b}$ Construction Research Centre, Universiti Teknologi Malaysia (UTM-CRC), \\ 81310 UTM Johor Bahru, Johor, Malaysia \\ ${ }^{c}$ Virginia Polytechnic Institute and State University, Faculty of Civil and \\ Environmental Engineering, Blacksburg, Virginia 24061, USA
}

Received 27 Nov 2012; accepted 09 Jan 2013

\begin{abstract}
Eurocode 4 design provisions specify two methods for the design of composite slabs, namely the $m-k$ and the partial shear connection (PSC) methods. Currently, the $m-k$ method includes the concrete thickness and the shear span of the slab as variables while the PSC method does not. This has resulted in a better accuracy for the $m-k$ method when slabs with varying dimensions are considered. It is demonstrated in this paper that the horizontal shear bond stress varies with the ratio of shear span to effective depth of slab, defined as the slenderness. To include such an effect, a linear shear bond-slenderness equation is proposed. Using the proposed relationship, a linear interpolation of shear bond strength based on two configurations, determined from the outcomes of the bending tests for compact and slender slabs, has been satisfactorily performed. The shear bond strength obtained from this interpolation can be used in collaboration with the existing PSC method, such that the accuracy of the prediction of the composite slab capacity can be considerably improved, the validity of which has been verified with published results from literatures.
\end{abstract}

Keywords: composite slab, shear bond, partial shear connection, $m-k$ method, linear regression.

\section{Introduction}

Nowadays, the use of the steel-concrete composite slab system is a common practice especially in the steel framed buildings. The system comprises normal or lightweight concrete placed permanently over a profiled cold-formed steel deck. Compared to the construction of ordinary reinforced concrete slab, the steel-concrete composite slab offers more advantages because the system is lighter and the handling of the steel deck is easier since the laborious preparation and placement of reinforcement bars in the slab can be circumvent. During construction, the deck acts as the mold for the fresh concrete, hence no temporary formwork is needed. When the concrete hardens, the deck acts as reinforcement for the composite slab system, eliminating the need for positive reinforcement bars.

Horizontal shear bond is always the main governing parameter that determines the behavior and strength of the steel-concrete composite slabs. In studying the influence of interfacial property of composite slabs, Valivonis (2006) explored the contact behavior between concrete and profiled steel sheeting in three stages: elastic, plastic deformation, and formation of cracks. It was found that the contact strength and hence the overall behavior of composite slab is extensively affected by the shape of the profiled sheeting, the pre-compressing force acting perpendicularly to the contact plane, and the horizontal forces that restrain the transversal strains of concrete. It has been shown in Abdullah and Easterling (2009) that the horizontal shear bond depends on the geometry of the slabs, the most important parameter of which is the ratio of the shear span to the effective depth, $L_{s} / d$, otherwise defined as the slenderness. Because the shear bond property is geometric dependent, its correct characterization is essential for design and numerical modeling purposes, so that an accurate prediction of the strength and behavior of the slab can be obtained. Such importance can be recognized through the influence of the slab slenderness on the maximum reaction force, as shown in Figure 1.

Corresponding author: Ahmad Beng Hong Kueh

E-mail:kbhahmad@utm.my 


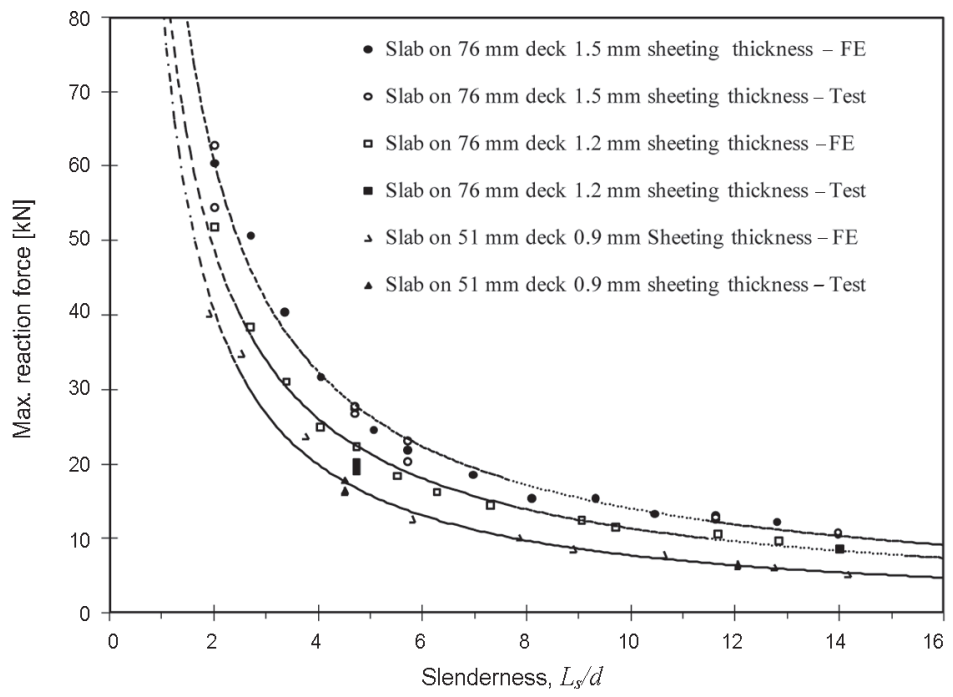

Fig. 1. Variation in the maximum reaction forces with respect to the slenderness of slab from the bending tests and FE analyses of simply supported composite slabs with a trapezoidal profiled steel deck (Abdullah, Easterling 2007, 2009)

\section{Methods for analyzing and designing composite slab}

Thus far, there exist several efforts in characterizing the interface shear bond behavior of steel-concrete composite slabs from numerous researchers in literature. To simplify the design and prediction of the behavior of composite slabs, Crisinel and Marimon (2004) proposed an approach that combines results from standard materials tests and small-scale tests with a simple calculation model to obtain the moment-curvature relationship at the critical crosssection. In their method, the load-carrying capacity of composite slabs was determined via the consideration of a three-phase moment-rotation behavior of the critical cross-sections, inputs of which include the geometric and material properties of steel and concrete and the characteristic description of the interface, as determined from the small-scale tests.

Several studies were devoted to the modeling of the shear bond behavior so far as the numerical method in particular the finite element (FE) approach is concerned. A special purpose FE procedure had been developed by Daniels and Crisinel (1993) with a material nonlinearity consideration, in which the shear interaction property was obtained from a pull out test, for analyzing composite slabs. Ferrer et al. (2006) modeled the pull-out tests of composite slabs, employing various coefficients of friction for the contact elements between the steel deck and the concrete. A calculation procedure was constructed by Abdullah and Easterling (2007) to obtain the shear bond property from bending tests, the behavior of which was then adopted for the connector elements that were used to model the steel-concrete interface of composite slabs. Tsalkatidis and Avdelas (2010) employed the use of nonmonotone material laws for the interface shear bond interaction, treating it as a two dimensional contact model, in modeling a simply supported one-span composite slab. In similar modeling representation, Tzaros et al. (2010) used a nonconvex-nonsmooth optimization technique for the mechanical description of the shear bonding. More recently, Chen and Shi (2011) presented a universal FE model for composite slabs, in which the shear bond interaction was modeled as a contact element incorporating both adhesion and friction, employing the Coulomb friction model, and considering both geometrical and material nonlinearities. Focusing on an independent modeling consideration of concrete and rolled embossments on the steel surface, Seres (2012) analyzed the composite action of the composite slabs to determine the interfacial shear resistance, due to complex behavior of mechanical and frictional interlocks.

Schuster (1970) pioneered the development of the ultimate shear bond equation for slabs exhibiting a shearbond failure mode. The method was adopted by ASCE (1992) in the form of the $m-k$ equation:

$$
\frac{V}{b d \sqrt{f_{c}^{\prime}}}=m \frac{\rho d}{L_{s} \sqrt{f_{c}^{\prime}}}+k
$$

where: $V$ is the shear force; $L_{s}$ the shear span; $f_{c}$ ' the concrete strength; $\rho$ the reinforcement ratio; and $b$ and $d$ are the width and effective depth of slab, respectively. $m$ and $k$ are the coefficients obtained from a linear regression.

By removing the concrete strength and substituting the reinforcement ratio with $\rho=\frac{A_{s}}{b d}$, Eqn (1) becomes:

$$
\frac{V}{b d}=m \frac{A_{s}}{b L_{s}}+k .
$$


Eqn (2) is the version of the $m-k$ method used in Eurocode 4 (2004). It reduces results dispersion produced by Eqn (1). This is in agreement with the findings of previous research in which the reason of dispersion is attributed to the concrete strength (Johnson 1994). It was found that Eqn (1) gives unsatisfactory $m$ and $k$, if the concrete compressive strength varies widely within a series of tests. In addition, works reported by Luttrell (1987), Daniels (1988), Bode and Saurborn (1992) and Veljkovic (1995) had confirmed that the concrete compressive strength does not influence the properties of slab significantly.

According to Seleim and Schuster (1985), neither the reinforcement ratio nor the concrete compressive strength has a significant influence on the shear bond resistance, but the steel thickness is a governing parameter. It is due to these findings that the removal of $f^{\prime}{ }_{c}$ from Eqn (1) and therefore the use of Eurocode's equation for designing composite slab, based on a series of test data, are preferred.

The $m-k$ method is thus far the most reliable tool for predicting composite slab strengths. Many researchers have used this method as a basis for comparison with the new design procedures that they developed. Notably new innovations include that incorporating perfobond (Jeong et al. 2009; Kim, Jeong 2010) as well as those with an introduction of additional concrete fillers, e.g. crumb rubber (Mohammed 2010) and palm oil clinker (Mohammed et al. 2011), all of which have implemented this regressed approach in the determination of the horizontal shear resistance of their structures. This exhibits the popularity and validity of the $m-k$ method for the design of steel-concrete composite slabs. It should be however noted that the $m-k$ method is a semi-empirical method that uses principally a statistical evaluation where the values of $m$ and $k$ are only applicable to specific slab configurations.

To overcome the deficiencies of the $m-k$ method, especially the lack of a mechanical model that reflects the influence of composite slab parameters, and to reduce dependency on full size tests, researchers in Europe have developed the partial shear connection (PSC) method. This method was first proposed by Stark (1978) and subsequently improved by Stark and Brekelmans (1990), Bode and Sauerborn (1992), Bode et al. (1996), and Bode and Dauwel (1999). The method was adopted in Eurocode 4 (2004) as an alternative to the $m-k$ method.

\section{Details of the PSC method}

In the PSC method (Eurocode 4 2004), the slab is assumed to fail by horizontal shear where the concrete can slip relatively to the steel deck without losing the load carrying capacity. In other words, the horizontal shear stress at the slip surface remains constant. This behavior requires a ductile shear failure.

The procedure for the PSC method begins with the generation of a theoretical partial interaction curve that is expressed using the relationship of $\frac{M}{M_{p, R m}}$ versus $\eta$, as shown in Figure 2(a). The curve is produced using the measured dimensions and strengths of concrete and steel components where $\eta$ is the intensity of interaction, for which the values are chosen at fixed intervals from 0 to 1 . $M$ and $M_{p, R m}$ are the moment resistances of composite slabs with partial interaction and full interaction, respectively.

Points A and C on the curve shown in Figure 2(a) are two extreme cases, corresponding to no interaction and full interaction where $M=0$ and $M=M_{p, R m}$, respectively. The corresponding stress blocks are depicted in Figure 2(b). The partial interaction state lies between these two points, for example at point B where $M$ is calculated following the stress block B in Figure 2(b):

$$
M=N_{c} z+M_{p r}
$$

where: $N_{c}$ - concrete compressive force under partial interaction; $z$ - moment arm whose value depends on the intensity of shear interaction; $M_{p r}$ - reduced moment capacity of the steel deck.

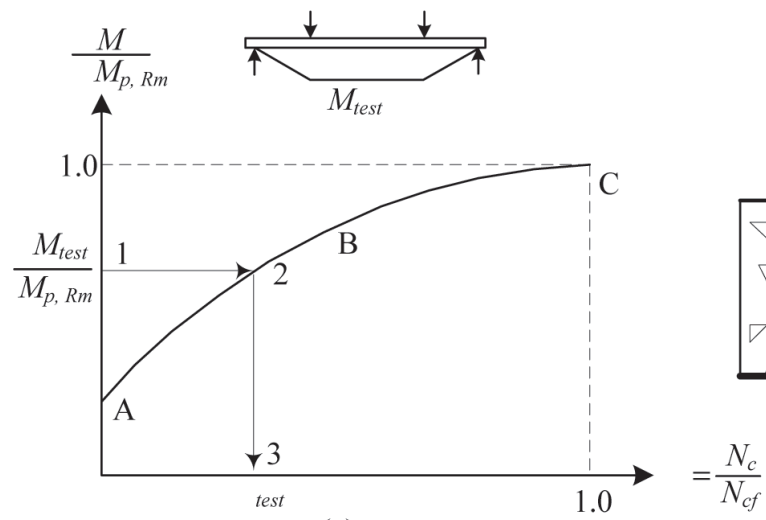

(a)

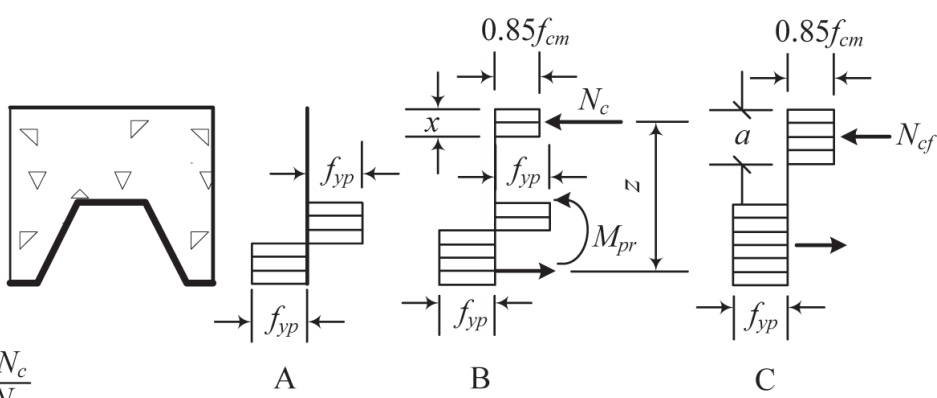

(b)

Fig. 2. Determination of the intensity of shear interaction using the PSC method: a) Partial interaction curve; b) Stress distributions at points A, B, and C (Eurocode 4 2004) 
Under partial interaction, the concrete compressive force constitutes only a fraction of that under full interaction, $N_{c f}$, and the amount depends on the intensity of interaction:

$$
N_{c}=\eta N_{c f}
$$

The moment arm takes the following form:

$$
z=h_{t}-0.5 x-e_{p}+\left(e_{p}-e\right) \eta
$$

where: $h_{t}$ - total slab thickness; $x$ - depth of concrete compressive zone; $e_{p}$ - distance from the plastic neutral axis of the steel deck to its extreme bottom fiber; $e$ - distance from the centroid of the effective area of the steel sheeting to its extreme bottom fiber.

The steel deck carries dual functions under partial composite interaction. Firstly, it serves as the tensile reinforcement in composite action, which is considered in the first term of Eqn (3). Second, it serves as an independent bending element where the deck bends about its own axis. The bending capacity is however reduced from the full capacity, depending on the amount of composite action. The reduced moment, $M_{p r}$, is defined as:

$$
M_{p r}=1.25 M_{p a}[1-\eta] \leq M_{p a},
$$

where: $M_{p a}$ is the plastic moment of the effective cross section of the steel deck. The depth of the concrete compressive zone, $x$, in Eqn (5) is given by:

$$
x=\frac{N_{c}}{b\left(0.85 f_{c m}\right)} \leq h_{c}
$$

where: $f_{c m}$ - concrete compressive strength; $h_{c}$ - thickness of the concrete cover above the steel deck.

$M_{p, R m}$ in the partial interaction curve is given by:

$$
M_{p, R m}=N_{c f}\left(d_{p}-0.5_{a}\right),
$$

where $a=\frac{A_{p} f_{y p}}{0.85 f_{c m} b}$ is the depth of the concrete compressive zone at full interaction. Here, $A_{p}$ and $f_{y p}$ are the effective area of the steel deck and the yield strength of the steel sheeting, respectively. $N_{c}$; the concrete compressive force under full interaction can be expressed as:

$$
N_{c f}=A_{p} f_{y p} .
$$

Eqns (3) to (9) are applicable to under-reinforced sections where the neutral axis lies in the concrete, which is the case for shallow depth profiles.

Having established all important parameters, the intensity of interaction can be next obtained from the partial interaction curve. In this step, full size tests are required from which the maximum bending moment, $M_{\text {test }}$, is determined. Using $M_{\text {test }}$, the intensity of interaction, $h_{\text {test }}$, can be obtained from the curve as shown by path 1-2-3 in Figure 2(a). Knowing the intensity of interaction, the ultimate shear bond stress, $\tau_{u}$, can be next calculated using:

$$
\tau_{u}=\frac{\eta_{t e s t} N_{c f}}{b\left(L_{s}+L_{0}\right)}
$$

where: $L_{s}$ - shear span; $L_{0}$ - overhanging length beyond support.

To satisfy the required level of confidence, Eurocode 4 suggests at least six full size tests to be performed to obtain the characteristic value of shear strength, $\tau_{u, R k}$. It also recommends the use of the minimum value of all tests, with a reduction of $10 \%$. The design strength of the shear connection, $\tau_{u, R d}$, is then obtained by dividing the characteristic strength with the partial safety factor for full shear resistance, $\gamma_{v}$ :

$$
\tau_{u, R d}=\frac{\tau_{u, R k}}{\gamma_{v}}
$$

Once the design shear strength is known, the design partial interaction curve or more exactly the design moment envelope for the particular deck profile can be drawn using Eqns (12) to (17), as given below:

$$
\begin{gathered}
M_{R d}=N_{c} z+M_{p r} ; \\
N_{c}=b L_{x} \tau_{u, R d} ; \quad L_{x} \leq L_{s f} ; \\
L_{s f}=\frac{N_{c f}}{b \tau_{u, R d}} ; \\
N_{c f}=A_{p} \frac{f_{y p}}{\gamma_{a p}} ; \\
z=h_{t}-0.5 x-e_{p}+\left(e_{p}-e\right) \frac{N_{c}}{N_{c f}} ; \quad N_{c} \leq N_{c f} ; \\
x=\frac{N_{c}}{b\left(0.85 \frac{f_{c k}}{\gamma_{c}}\right)} \leq h_{c}
\end{gathered}
$$

where: $M_{R d}$ - design value of the resisting bending moment in partial interaction mode, i.e. the moment envelope; $M_{p, R d}$ - maximum resisting moment for the particular profile at full interaction; $L_{x}$ - distance between supports, representing the beam length; $L_{s f}$ - shear span required for full shear connection; $\gamma_{a p}$ - partial safety factor for profiled steel sheeting; $\gamma_{c}-$ partial safety factor for concrete; $f_{c k}$ - characteristic compressive strength of concrete.

One example of such a plot is illustrated in Figure 3.

The design partial interaction curve is independent of loading type and magnitude. Hence, the allowable loads of, for examples, beams A and B in Figure 3, can be determined easily by plotting the applied moment diagram, $M_{s d}$, below or just touching the envelope of the design curve. 


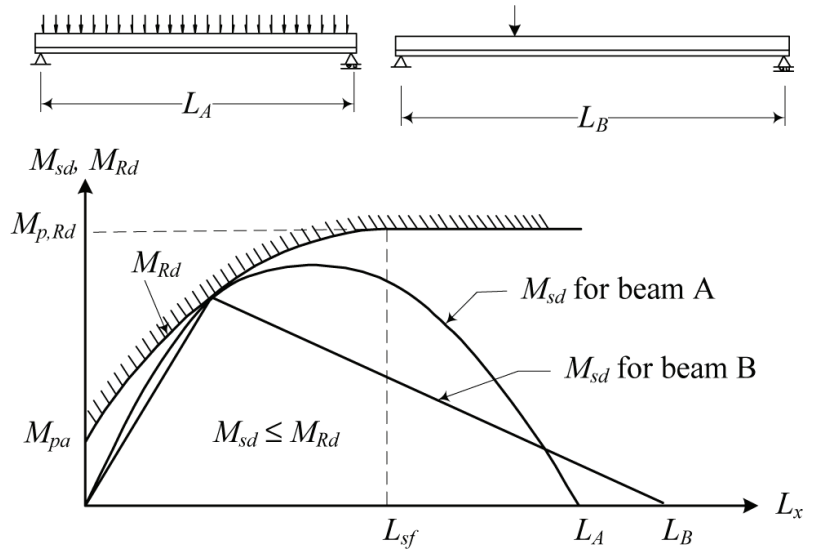

Fig. 3. Partial interaction moment curve

One advantage of the PSC method is that it is based on a clear mechanical model where the effect of other parameters such as the end anchorage, additional reinforcement and the friction at the support can be incorporated separately in the equations. The use of the plastic design for continuous composite slabs is also possible (Bode 1996; Bode, Dauwel 1999). A procedure to incorporate the effects of end anchorage, frictional interlock, and mechanical interlock in the PSC method was proposed by Calixto et al. (1998). They suggested a plot of test data using $\frac{V_{u t}}{b\left(L_{s}+L_{o}\right)}$ for the horizontal axis and $\tau_{u}=\frac{\eta N_{c f}}{b\left(L_{s}+L_{o}\right)}$ for the vertical axis such that a regression line can be formed for the interaction curve. The corresponding equation is:

$$
\frac{\eta N_{c f}}{b\left(L_{s}+L_{o}\right)}=\tau_{u m}+\frac{\mu V_{u t}}{b\left(L_{s}+L_{o}\right)}
$$

where: $\tau_{u m}$ - mechanical shear bond strength; $\mu$-friction coefficient, values of which are given by the intercept and the slope of the regression line, respectively. This method shows a much better correlation with the test data when compared to that of the $m-k$ method.

\section{Weakness of the present PSC method}

As indicated in Figure 1, the slab slenderness, $L_{s} d$, affects substantially the behavior of composite slab. The PSC method, which is adopted in Eurocode 4 (2004), does not properly address the effect of slab slenderness when the intensity of interaction, $\eta$, is determined from a test, as illustrated in Figure 2(a). Here, it is obvious that the ultimate moment obtained from the test, which is required to determine the intensity of interaction, $\eta$, depends on the slab thickness and the shear span. Slender slabs, i.e. with large $L_{s} / d$ yield low ultimate moment whereas the opposite is true for compact slabs ( $\left(s m a l l ~ L_{s} / d\right.$ ). As a result, various intensities of interaction, $\eta$, and accordingly several shear bond strengths, $\tau_{u}$, as given in Eqn (10), exist for the slab specimens built with the same deck type.
Abdinasir et al. (2012) have proposed and quantified $L_{s} / d=$ 7.0 as the ratio that divides the definition for composite slabs into slender and compact based on the observation first made by Abdullah and Easterling (2009) in regard to the recommendation given in Annex B (B.3.2 Testing arrangement) of Eurocode 4 in which at least 3 groups of specimens must be conducted each in regions $\mathrm{A}$ and B (Fig. 4), the chief parameter of which is the slenderness ratio, $L_{s} / d$. In this case, they have defined regions $\mathrm{A}$ and $\mathrm{B}$ for slender and compact slabs, respectively. On close inspection, they observed in their work that reaction force of composite slab experiences an exponential drop within a certain range of $L_{s} / d$ as this ratio increases. The reaction force shows however little change even though $L_{s} / d$ is increased when a certain $L_{s} / d$ is reached, the value of which has been quantified as 7.0 by Abdinasir et al. (2012), i.e. $L_{s} / d<7$ for compact while $L_{s} / d \geq 7$ for slender slabs. Note that the dividing ratio, $L_{s} / d=7.0$, is characterized through observation for definition convenience.

This implies that if the shear strength obtained from the tests of compact slabs is used to design a slender slab, the resulting design can be unsafe for practical use. On the other hand, if a compact slab is designed based on the shear strength obtained from the tests of slender slabs, an overly conservative design may be produced. Eurocode 4 specifies that the test specimens for determining the design value of the longitudinal shear strength, $\tau_{u}$, should be as long as possible (as slender as possible) such that the failure by longitudinal shear can be formed. As a result, the evaluation of a slab with slenderness lower than the test specimen by the PSC method is always conservative and potentially uneconomical. In this paper, an improvement in the determination of the ultimate shear bond strength, $\tau_{u}$, used in the PSC method, which takes into account the slab slenderness, is therefore proposed.

\section{Establishing a relationship between shear bond stress and slenderness}

Since the shear bond strength varies with the slenderness, a single value of $\tau_{u}$ cannot represent the overall range of slab slenderness accurately. Therefore, the improvement

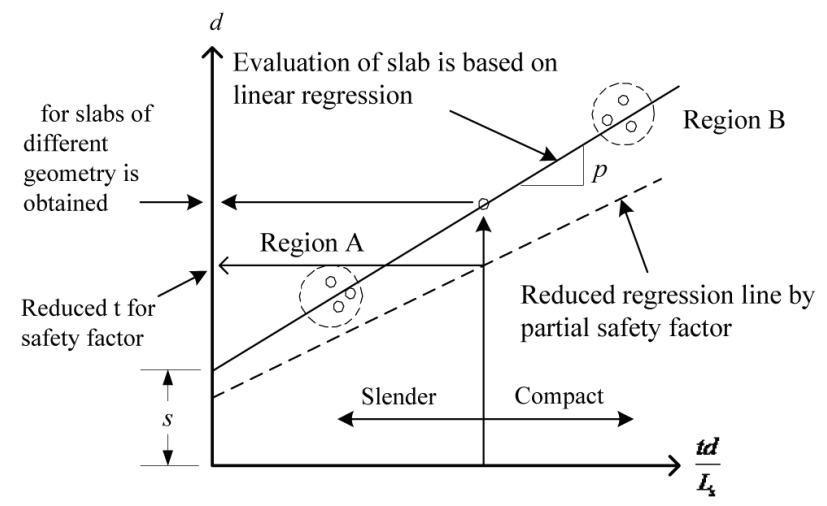

Fig. 4. Determination of the ultimate shear bond strength for the use in the PSC method 
should be made such that $\tau_{u}$ is represented as a function of slab slenderness.

Consider a free body diagram in Figure 5 for a typical shear bond failure as assumed in the partial shear connection theory. By taking moments about the compressive force, $C$, and considering that the moment arm differs very slightly from the slab effective depth, the moment equilibrium equation can be estimated as:

$$
V L_{s}=T d+M_{r}
$$

Substituting $T$ with $\tau\left(L_{S}+L_{o}\right) b$, Eqn (19) becomes:

$$
V L_{s}=\tau\left(L_{s}+L_{o}\right) b d+M_{r},
$$

where $M_{r}$ is the remaining moment strength in the deck.

Eqn (20) is an approximation because the lever arm is always less than the effective depth. Nevertheless, for composite slabs, the difference is insignificant because after the initiation of shear slip, the crack tip grows upward quite rapidly, bringing the composite neutral axis close to the top fiber and hence the lever arm to the effective depth, $d$.

Rearranging Eqn (20) and substituting it into Eqn (2), a new equation relating shear bond stress to the slab geometry is obtained:

$$
\tau d=m \frac{A_{s}}{b} \frac{d}{\left(L_{s}+L_{o}\right)}+\left(\frac{k b d L_{s}-M_{r}}{b\left(L_{s}+L_{o}\right)}\right) .
$$
If $b$ is taken as the length of the steel sheeting, then $\frac{A_{s}}{b}$
is equal to the thickness, $t$, of the steel deck. We therefore have:

$$
\tau d=m \frac{t d}{\left(L_{s}+L_{o}\right)}+\left(\frac{k b d L_{s}-M_{r}}{b\left(L_{s}+L_{o}\right)}\right) .
$$

It should be noted that the derivation of Eqn (22) is based on the consideration that a uniform distribution of shear bond stress, $\tau$, is formed throughout the surface area of the steel-concrete interface and along the length measured from the applied load to the slab's end.

When deriving the original $m-k$ equation, Schuster (1970) neglected the contribution of the remaining moment strength, $M_{r}$ in the steel deck and so did Patrick and Bridge (1994), Veljkovic (1996) and Widjaja and Easterling (1996) in their modified PSC methods. It was shown that the second term of the right hand side of Eqn (22) acts collectively as a constant regardless of the value of $M_{r}$ and therefore a detailed determination of this term is not needed. Following this reasoning, Eqn (22) can be simplified to:

$$
\tau d=m \frac{t d}{\left(L_{s}+L_{o}\right)}+k
$$

Also, the overhanging length, $L_{o}$, is usually short. Therefore, it is assumed here that $L_{o}$ is not a determining factor for the slab behavior and it can be removed from the equation, to give:

$$
\tau d=m \frac{t d}{L_{s}}+k
$$

It should be noted that the contribution of $L_{o}$ to the horizontal shear resistance cannot be neglected when $\tau$ is calculated using Eqn (10). Eqn (24) is a linear equation, written in a similar manner as that of the $m-k$ equation. To facilitate extensive reference to Eqn (24) in the remainder of this paper, and to differentiate its variables $m$ and $k$ from the $m-k$ method, Eqn (24) is subsequently called the shear bond-slenderness equation and the slope and the intercept obtained from the linear regression are changed to $p$ and $s$ replacing respectively $m$ and $k$. The term $d / L_{s}$ is defined as the slab compactness while its inverse, $L_{s} / d$ is readily known as the slab slenderness. The shear bondslenderness equation is now expressed as:

$$
\tau d=p \frac{t d}{L_{s}}+s
$$

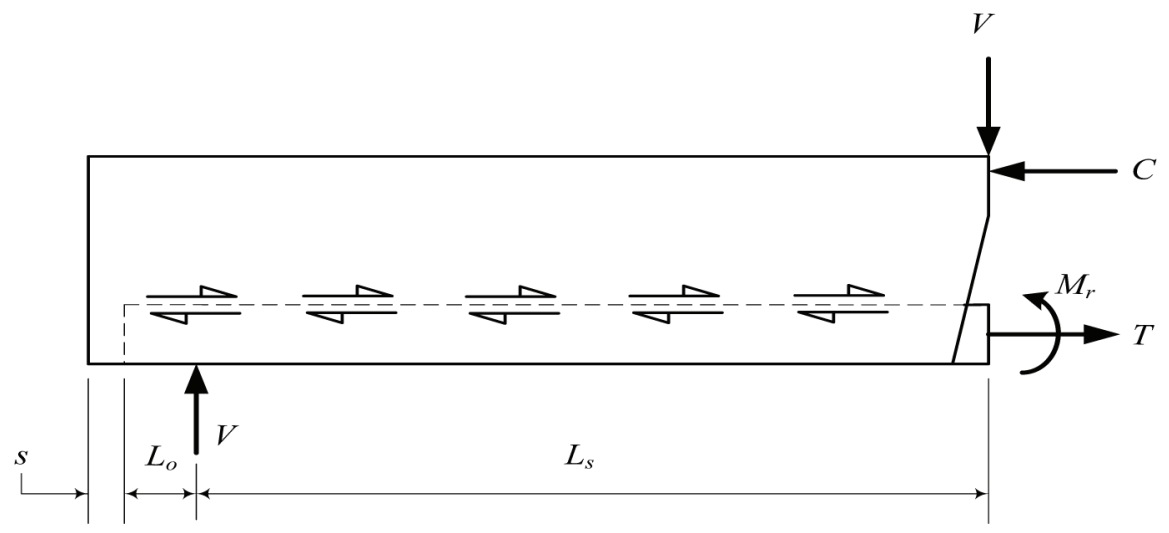

Fig. 5. Free body diagram of the shear span region for slab that fails by shear bond 


\section{Application of the shear bond-slenderness equation}

The method to assess the moment capacity of a slab using the shear bond-slenderness equation follows the same procedure as that of the $m-k$ method. Firstly, a sufficient number of bending tests of slabs (in accordance with the testing procedure given in Eurocode 4) should be conducted for two configurations: slender and compact configurations (regions A and B, respectively, in Fig. 4). From the tests, the maximum shear bond stress, $\tau_{u}$, for each test is calculated in accordance with Figure 2(a) and Eqn (10) such that a relationship between $\tau d$ and $t d / L_{s}$ can be formed as shown in Figure 4, using a linear regression line. The line is used to interpolate the shear bond strength of slabs with different spans, and different concrete and sheeting thicknesses. As suggested in the testing procedure of Eurocode 4, the shear span is to be taken as a quarter of the total length of the slab. The shear bond is then used in the determination of the moment resistance of the slab in accordance with the PSC method specified in Eurocode 4. Also, a reduced regression line may be considered adopting a safety factor, as implemented in the $m-k$ method.

\section{Verification of the proposed shear bond- slenderness equation}

A set of bending test data for the composite slabs constructed using the trapezoidal shape steel deck shown in Figure 6, as reported in Abdullah and Easterling (2007), is used to verify the proposed shear bond-slenderness equation. Results from the finite element analyses based on the same test data that were reported in Abdullah and Easterling (2009) and presented in Figure 1 are also analyzed. The finite element results are for the slabs whose geometries (span and concrete thickness) differ from those of test specimens. They are for slabs built on $76 \mathrm{~mm}$ deck with $1.5 \mathrm{~mm}$ and $1.2 \mathrm{~mm}$ sheeting thicknesses and on $51 \mathrm{~mm}$ deck with $0.9 \mathrm{~mm}$ sheeting thickness. The details of the finite element analysis can be referred in Abdullah et al. (2007).

Using the maximum loads obtained from the bending tests and the finite element analyses, the maximum shear bond stress of each slab is calculated in accordance with the PSC method (Fig. 2(a) and Eqn (10)). The parameters required for plotting the shear bond-slenderness relationship are tabulated in Table 1 and Table 2 for the test and finite element results, respectively. The main relationships are presented in Figure 7 to Figure 10. Clearly, all results fall along a straight line, which confirms the validity of the proposed equation.

It should be noted that the incorporation of sheeting thickness, $t$, in the shear bond-slenderness equation enables all slabs to be built on the same deck profile but with different sheeting thicknesses for the bending test and assessment of the shear bond. This is shown in Figure 7 to Figure 10 where the plots are from a combination of tests on slab specimens using decks with $0.9 \mathrm{~mm}, 1.2 \mathrm{~mm}$ and $1.5 \mathrm{~mm}$ sheeting thicknesses. Using the data from the tests for slabs that are built on the same deck but with the thickness different from the test specimen, the determined shear bond is in agreement with the findings of Seleim and Schuster (1985) and the results produced using the Canadian Sheet Steel Building Institute (CSSBI) specification (1996).

\section{Design example}

For convenience, we demonstrate next the design procedure for composite slabs that are studied in this paper. In this example, test specimens \#5 and \#9 for slabs using $76 \mathrm{~mm}$ deck as shown in Table 1 are used to calculate the intensity of interaction, $\eta$ (Fig. 2(a)), and shear bond stress, $\tau$ (Eqn (10)), respectively. These values are plotted to form the relationship of $\tau d$ versus $t d / L_{s}$ (Eqn (25)), from which $p$ and $s$ are obtained from a regression line (Table 3 ). With these parameters, $\tau_{u}$ for other slabs with different thicknesses and shear spans are obtained by linear interpolation in accordance with Eqn (10). Once $\tau_{u}$ for the corresponding slabs are obtained, the ultimate loads for these slabs are calculated according to Eqns (12) to (17), as shown graphically in Figure 3. A partial safety factor of 1.0 is used in this exercise. The same procedure is repeated for $51 \mathrm{~mm}$ deck slabs based on tests \#10 and \#11 of Table 1 where the calculation outputs are shown in Table 3. For comparison, the ultimate load predictions adopting the $m-k$ method (Eqn (2)), using the data from the same specimens are also performed (Table 4). The results from both methods are compared with the elemental and full size test data reported in Abdullah and Easterling $(2007,2009)$ by computing the ratio of testto-calculated values. The results are tabulated in Table 5.

For the improved PSC method, the mean of the ratios of elemental test-to-calculated values is 1.08 with a $10 \%$ average variation of the test values from those

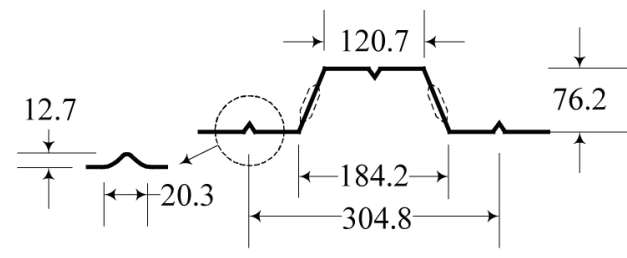

Cross section of $76 \mathrm{~mm}$ deck

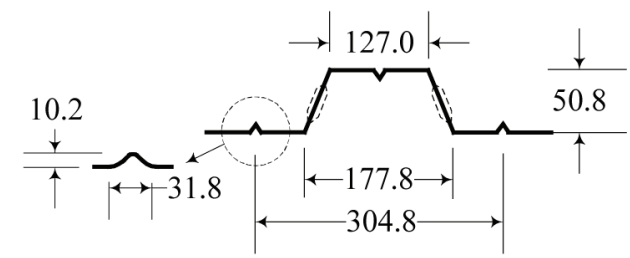

Cross section of $51 \mathrm{~mm}$ deck

Fig. 6. Deck's cross sections and dimensionsin millimeters (Abdullah, Easterling 2007, 2009). 
Table 1. Results from elemental tests (Abdullah, Easterling 2007)

\begin{tabular}{|c|c|c|c|c|c|c|c|c|c|}
\hline Specimen \# & $\begin{array}{l}\text { Deck depth } \\
\quad(\mathrm{mm})\end{array}$ & $\begin{array}{l}\text { Sheeting } \\
\text { thickness, } \\
t(\mathrm{~mm})\end{array}$ & $\begin{array}{c}\text { Shear span, } \\
L_{s}\end{array}$ & $\begin{array}{l}\text { Effective } \\
\text { depth, } d \\
(\mathrm{~mm})\end{array}$ & $t d / L_{\mathrm{s}}$ & Test & $\begin{array}{c}\text { Failure } \\
\text { load }(\mathrm{kN} / \\
\left.\mathrm{m}^{2}\right)\end{array}$ & $\begin{array}{c}\tau \text { by PSC } \\
(\mathrm{MPa})\end{array}$ & $\tau d(\mathrm{~N} / \mathrm{mm})$ \\
\hline \multirow{2}{*}{1} & \multirow{2}{*}{76} & \multirow{2}{*}{0.9} & \multirow{2}{*}{810} & \multirow{2}{*}{147} & \multirow{2}{*}{0.163} & A & 67 & 0.210 & 30.87 \\
\hline & & & & & & B & 66 & 0.205 & 30.14 \\
\hline \multirow{2}{*}{2} & \multirow{2}{*}{76} & \multirow{2}{*}{0.9} & \multirow{2}{*}{1020} & \multirow{2}{*}{84} & \multirow{2}{*}{0.074} & A & 24 & 0.221 & 18.56 \\
\hline & & & & & & B & 20 & 0.135 & 11.34 \\
\hline \multirow{2}{*}{3} & \multirow{2}{*}{76} & \multirow{2}{*}{1.2} & \multirow{2}{*}{810} & \multirow{2}{*}{151} & \multirow{2}{*}{0.224} & A & 71 & 0.204 & 30.80 \\
\hline & & & & & & $\mathrm{B}$ & 75 & 0.224 & 33.82 \\
\hline \multirow{2}{*}{4} & \multirow{2}{*}{76} & \multirow{2}{*}{1.2} & \multirow{2}{*}{1320} & \multirow{2}{*}{87} & \multirow{2}{*}{0.079} & A & 20 & 0.181 & 15.75 \\
\hline & & & & & & B & 20 & 0.188 & 16.36 \\
\hline \multirow{2}{*}{5} & \multirow{2}{*}{76} & \multirow{2}{*}{1.5} & \multirow{2}{*}{410} & \multirow{2}{*}{151} & 0552 & A & 487 & 0.600 & 90.60 \\
\hline & & & & & 0.532 & B & 422 & 0.467 & 70.52 \\
\hline 6 & 76 & 15 & 810 & 151 & 028 & A & 101 & 0.301 & 45.45 \\
\hline 0 & 10 & 1.5 & 010 & 131 & 0.20 & $\mathrm{~B}$ & 103 & 0.316 & 47.72 \\
\hline 7 & 76 & 15 & 970 & 151 & 0234 & A & 65 & 0.270 & 40.77 \\
\hline 1 & 10 & 1.0 & 年 & 101 & T.25 & B & 57 & 0.217 & 32.77 \\
\hline 8 & 76 & 15 & 1120 & 87 & 0117 & A & 29 & 0.244 & 21.23 \\
\hline 0 & 10 & 1.5 & 1120 & 01 & 0.117 & B & 29 & 0.248 & 21.58 \\
\hline 0 & 76 & 15 & 1220 & 87 & $0 \Omega 00$ & A & 21 & 0.198 & 17.23 \\
\hline 9 & 10 & 1.5 & 1320 & 01 & 0.099 & $\mathrm{~B}$ & 21 & 0.217 & 18.88 \\
\hline 10 & 51 & 09 & 710 & 135 & 0171 & A & 77 & 0.266 & 35.91 \\
\hline 10 & 1 & 0. & 110 & 10 & 0.171 & B & 71 & 0.236 & 31.86 \\
\hline 11 & 51 & 09 & 970 & 72 & 0067 & A & 23 & 0.163 & 11.74 \\
\hline 11 & $J 1$ & 0.9 & 要 & 12 & 0.001 & B & 22 & 0.149 & 10.73 \\
\hline 12 & 51 & 12 & 710 & 137 & 0232 & A & 88 & 0.287 & 39.32 \\
\hline 12 & 31 & 1.2 & 110 & 151 & 0.252 & $\mathrm{~B}$ & 93 & 0.314 & 43.02 \\
\hline 13 & 51 & 12 & 1070 & 74 & 0083 & A & 22 & 0.239 & 17.69 \\
\hline 10 & נו & 1.2 & 1070 & 17 & 0.003 & B & 22 & 0.240 & 17.76 \\
\hline 14 & 51 & 15 & 710 & 138 & 0292 & A & 125 & 0.443 & 61.13 \\
\hline 14 & 31 & 1.5 & 110 & 100 & 0.292 & B & 114 & 0.390 & 53.82 \\
\hline 15 & 51 & 15 & 1170 & 74 & 0005 & A & 23 & 0.286 & 21.16 \\
\hline 13 & 31 & 1.0 & 1170 & 14 & 0.093 & B & 24 & 0.319 & 23.61 \\
\hline
\end{tabular}

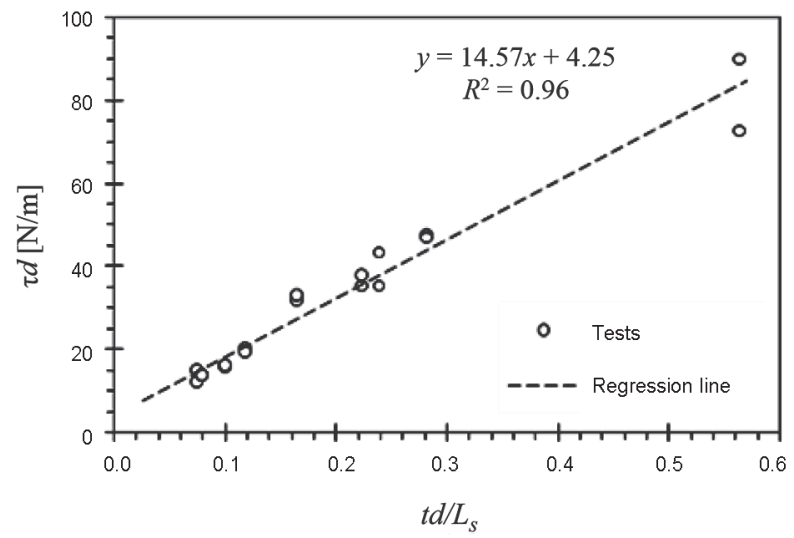

Fig. 7. $\tau d$ versus $t d / L_{s}$ for the tests of slab specimens using $76 \mathrm{~mm}$ deck with $0.9,1.2$ and $1.5 \mathrm{~mm}$ sheeting thicknesses (Specimens \#1 - \#9 of Table 1)

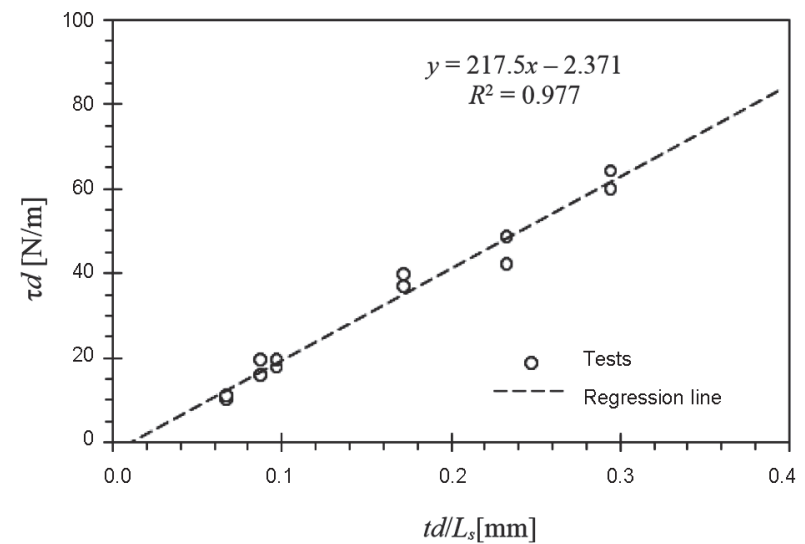

Fig. 8. $\tau d$ versus $t d / L_{s}$ for the tests of slab specimens using $51 \mathrm{~mm}$ deck with $0.9,1.2$, and $1.5 \mathrm{~mm}$ sheeting thicknesses (Specimens \#10 - \#15 of Table 1) 
Table 2. Results from FE analyses of slabs using $76 \mathrm{~mm}$ deck with $1.5 \mathrm{~mm}$ and $1.2 \mathrm{~mm}$ sheeting thicknesses and $51 \mathrm{~mm}$ deck with $0.9 \mathrm{~mm}$ sheeting thickness (Abdullah, Easterling 2009)

\begin{tabular}{|c|c|c|c|c|c|c|c|c|}
\hline FE model \# & $\begin{array}{l}\text { Deck depth } \\
\quad(\mathrm{mm})\end{array}$ & $\begin{array}{c}\text { Sheeting } \\
\text { thickness, } \\
t(\mathrm{~mm})\end{array}$ & $\begin{array}{c}\text { Shear span, } \\
L_{s}\end{array}$ & $\begin{array}{l}\text { Effective } \\
\text { depth, } d \\
(\mathrm{~mm})\end{array}$ & $t d / L_{\mathrm{s}}$ & $\begin{array}{l}\text { Max. load } \\
\left(\mathrm{kN} / \mathrm{m}^{2}\right)\end{array}$ & $\begin{array}{c}\tau \text { by PSC } \\
(\mathrm{MPa})\end{array}$ & $\begin{array}{c}\tau d \\
(\mathrm{~N} / \mathrm{mm})\end{array}$ \\
\hline 1 & 76 & 1.5 & 410 & 151 & 0.564 & 470 & 0.564 & 85.11 \\
\hline 2 & 76 & 1.5 & 510 & 151 & 0.451 & 311 & 0.544 & 82.01 \\
\hline 3 & 76 & 1.5 & 610 & 151 & 0.376 & 204 & 0.448 & 67.63 \\
\hline 4 & 76 & 1.5 & 710 & 151 & 0.322 & 137 & 0.350 & 52.87 \\
\hline 5 & 76 & 1.5 & 810 & 151 & 0.282 & 102 & 0.309 & 46.62 \\
\hline 6 & 76 & 1.5 & 860 & 151 & 0.265 & 77 & 0.275 & 41.46 \\
\hline 7 & 76 & 1.5 & 970 & 151 & 0.237 & 61 & 0.246 & 37.14 \\
\hline 8 & 76 & 1.5 & 1070 & 138 & 0.197 & 59 & 0.233 & 32.22 \\
\hline 9 & 76 & 1.5 & 1020 & 113 & 0.169 & 45 & 0.201 & 22.63 \\
\hline 10 & 76 & 1.5 & 910 & 87 & 0.145 & 40 & 0.257 & 22.42 \\
\hline 11 & 76 & 1.5 & 1020 & 87 & 0.131 & 33 & 0.224 & 19.57 \\
\hline 12 & 76 & 1.5 & 1120 & 87 & 0.119 & 28 & 0.229 & 19.98 \\
\hline 13 & 76 & 1.5 & 1220 & 87 & 0.109 & 26 & 0.248 & 21.66 \\
\hline 14 & 76 & 1.5 & 1320 & 87 & 0.100 & 21 & 0.212 & 18.52 \\
\hline 15 & 76 & 1.2 & 410 & 151 & 0.446 & 401 & 0.523 & 78.65 \\
\hline 16 & 76 & 1.2 & 510 & 151 & 0.357 & 235 & 0.412 & 62.02 \\
\hline 17 & 76 & 1.2 & 610 & 151 & 0.297 & 157 & 0.351 & 52.91 \\
\hline 18 & 76 & 1.2 & 710 & 151 & 0.255 & 107 & 0.282 & 42.40 \\
\hline 19 & 76 & 1.2 & 810 & 151 & 0.223 & 83 & 0.264 & 39.77 \\
\hline 20 & 76 & 1.2 & 860 & 138 & 0.192 & 57 & 0.232 & 31.99 \\
\hline 21 & 76 & 1.2 & 970 & 138 & 0.172 & 46 & 0.208 & 28.64 \\
\hline 22 & 76 & 1.2 & 1020 & 125 & 0.148 & 35 & 0.202 & 25.23 \\
\hline 23 & 76 & 1.2 & 1120 & 112 & 0.121 & 28 & 0.198 & 22.28 \\
\hline 24 & 76 & 1.2 & 1200 & 112 & 0.113 & 28 & 0.183 & 20.52 \\
\hline 25 & 76 & 1.2 & 1120 & 87 & 0.094 & 24 & 0.220 & 19.15 \\
\hline 26 & 76 & 1.2 & 1220 & 87 & 0.086 & 20 & 0.200 & 17.43 \\
\hline 27 & 76 & 1.2 & 1320 & 87 & 0.079 & 20 & 0.179 & 15.57 \\
\hline 28 & 51 & 0.9 & 410 & 161 & 0.359 & 312 & 0.441 & 70.86 \\
\hline 29 & 51 & 0.9 & 510 & 161 & 0.287 & 213 & 0.426 & 68.42 \\
\hline 30 & 51 & 0.9 & 610 & 135 & 0.202 & 120 & 0.357 & 48.23 \\
\hline 31 & 51 & 0.9 & 710 & 135 & 0.173 & 70 & 0.232 & 31.42 \\
\hline 32 & 51 & 0.9 & 810 & 123 & 0.137 & 47 & 0.197 & 24.19 \\
\hline 33 & 51 & 0.9 & 860 & 97 & 0.102 & 32 & 0.203 & 19.73 \\
\hline 34 & 51 & 0.9 & 860 & 72 & 0.076 & 24 & 0.197 & 14.10 \\
\hline 35 & 51 & 0.9 & 970 & 72 & 0.068 & 23 & 0.154 & 11.04 \\
\hline 36 & 51 & 0.9 & 970 & 97 & 0.091 & 24 & 0.168 & 16.27 \\
\hline 37 & 51 & 0.9 & 1020 & 72 & 0.064 & 15 & 0.150 & 10.75 \\
\hline 38 & 51 & 0.9 & 1120 & 72 & 0.058 & 12 & 0.122 & 8.72 \\
\hline
\end{tabular}

calculated, as indicated by a standard deviation of 0.10 . For the $m-k$ method, the same comparisons of the ratios give 1.13 and 0.11 for the mean and standard deviation, respectively. For full size specimens, the PSC method gives a mean and a standard deviation of 1.07 and 0.17 , respectively. They are 1.11 and 0.12 , respectively, for the $m-k$ method. Graphical comparison between the calculated ultimate loads and the tests data for elemental and full size tests are depicted in Figure 11 and Figure 12, respectively. It can be seen that both methods are relatively conservative compared to the test results in the region represented by compact slabs, where the 


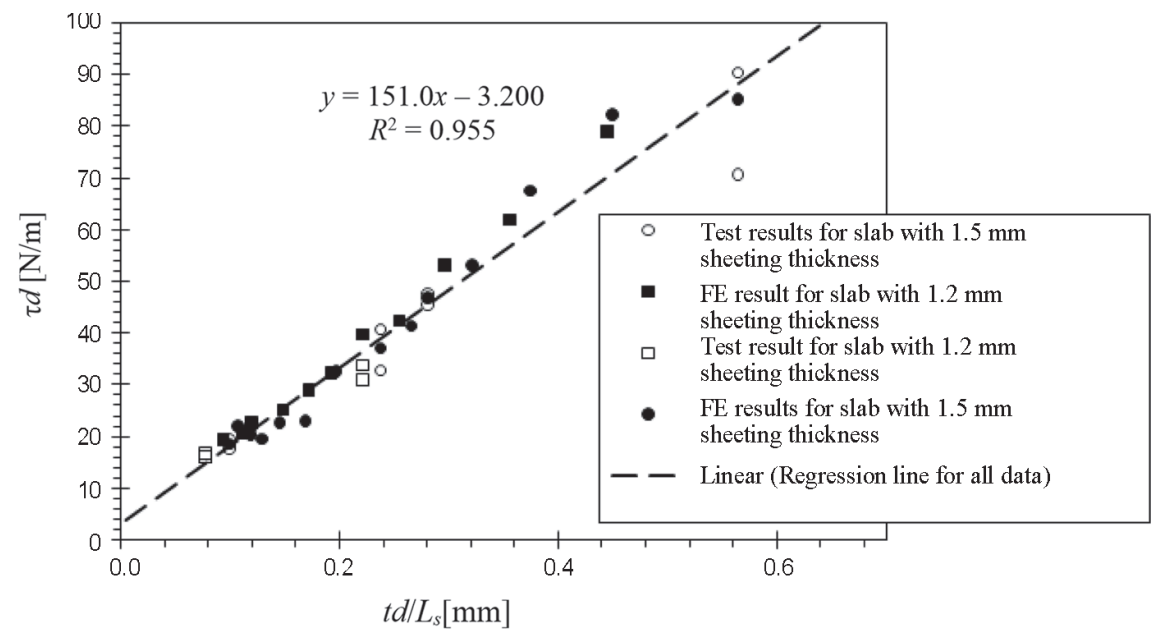

Fig. 9. $\tau d$ versus $t d / L_{s}$ for combined results for slabs on $76 \mathrm{~mm}$ deck and $1.2 \mathrm{~mm}$ and $1.5 \mathrm{~mm}$ sheeting thicknesses (FE models \#1 - \#27 of Table 2 and test data of specimens \#1 - \#9 of Table 1)

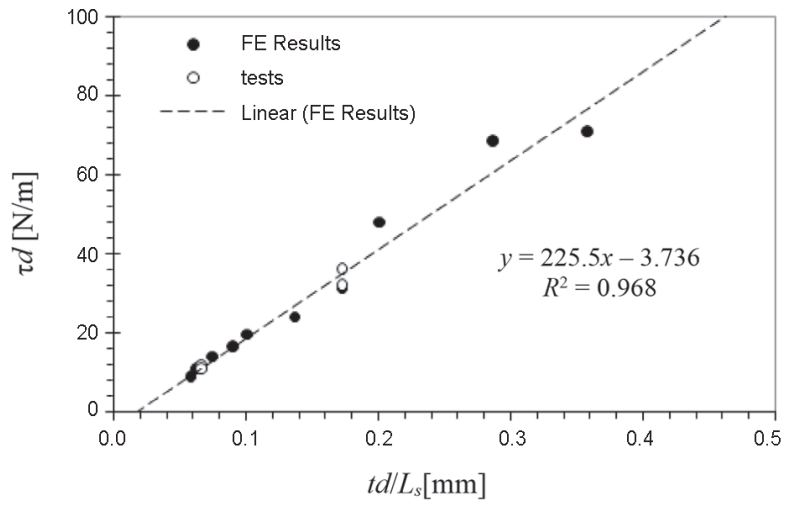

Fig. 10. $\tau d$ versus $t d / L_{s}$ for combined results for slabs on $51 \mathrm{~mm}$ deck with various sheeting thicknesses (FE models \#28 - \#38 of Table 2 and test data of specimens \#10 - \#15 of Table 1) elemental test loads are within $20 \%$ higher than those calculated while the full size test loads are within $40 \%$ greater. In the region represented by slender slabs, both loads from tests and calculations are in better agreement.

It can be demonstrated that the ultimate load calculated using the improved PSC method employing the shear bond-slenderness equation is as accurate as that calculated using the $m-k$ method. Such comparison is depicted in Figure 13. This implies that the PSC method has been greatly improved using the proposed shear bond-slenderness equation. Hence, the procedure can be used to design slabs of various slendernesses with better accuracy using only two sets of test data. A direct comparison between the improved PSC and the $m-k$ methods is now possible because the shear bond-slenderness equation used in the PSC method employs the concept of linear interpolation similar to the $m-k$ equation.

Table 3. Design parameters according to the PSC method with the application of the shear bond-slenderness equation

\begin{tabular}{|c|c|c|c|c|c|c|c|c|c|c|c|c|}
\hline $\begin{array}{c}\text { Specimen } \\
\#\end{array}$ & $\begin{array}{c}\text { Test } \\
\#\end{array}$ & $\begin{array}{c}\text { Max. } \\
\text { moment } \\
\text { from test, } \\
M_{\text {test }} \\
(\mathrm{kN}-\mathrm{m})\end{array}$ & $\begin{array}{c}\text { Theoritical } \\
M_{\mathrm{p}, \mathrm{Rm}} \\
(\mathrm{kN}-\mathrm{m})\end{array}$ & $\begin{array}{l}\text { Intensity } \\
\text { of shear } \\
\text { conn., } \eta\end{array}$ & $\begin{array}{c}\text { Ultimate } \\
\text { shear } \\
\text { bond } \\
\text { stress, } \\
\tau(\mathrm{MPa})\end{array}$ & $\begin{array}{c}\text { Deck } \\
\text { thickness, } \\
t(\mathrm{~mm})\end{array}$ & $\begin{array}{l}\text { Effective } \\
\text { depth, } \\
d(\mathrm{~mm})\end{array}$ & $\begin{array}{c}\text { Shear } \\
\text { span, } \\
L_{S}(\mathrm{~mm})\end{array}$ & $\tau d$ & $t d / L_{s}$ & $p$ & $s$ \\
\hline \multirow{2}{*}{5} & A & 0.230 & 0.383 & 0.456 & 0.600 & 1.5 & 151 & 410 & 90.60 & 0.552 & \multirow{4}{*}{137.98} & \multirow{4}{*}{4.39} \\
\hline & B & 0.199 & 0.383 & 0.355 & 0.467 & 1.5 & 151 & 410 & 70.52 & 0.552 & & \\
\hline \multirow{2}{*}{9} & A & 0.155 & 0.209 & 0.489 & 0.198 & 1.5 & 87 & 1320 & 17.23 & 0.099 & & \\
\hline & B & 0.161 & 0.209 & 0.537 & 0.217 & 1.5 & 87 & 1320 & 18.88 & 0.099 & & \\
\hline \multirow{2}{*}{10} & A & 0.131 & 0.197 & 0.580 & 0.266 & 0.9 & 135 & 710 & 35.91 & 0.171 & \multirow{4}{*}{218.22} & \multirow{4}{*}{-3.43} \\
\hline & B & 0.120 & 0.197 & 0.516 & 0.236 & 0.9 & 135 & 710 & 31.86 & 0.171 & & \\
\hline \multirow{2}{*}{11} & A & 0.068 & 0.099 & 0.483 & 0.163 & 0.9 & 72 & 970 & 11.74 & 0.067 & & \\
\hline & B & 0.065 & 0.099 & 0.442 & 0.149 & 0.9 & 72 & 970 & 10.73 & 0.067 & & \\
\hline
\end{tabular}


Table 4. Design parameters according to the $m-k$ method

\begin{tabular}{|c|c|c|c|c|c|c|c|c|c|c|}
\hline Specimen \# & Test & $\begin{array}{l}\text { Max. } V_{\text {test }} \\
\quad(\mathrm{kN})\end{array}$ & $b(\mathrm{~mm})$ & $L_{s}(\mathrm{~mm})$ & $A_{p}(\mathrm{~mm})$ & $d(\mathrm{~mm})$ & $\frac{A_{p}}{b L_{s}}$ & $\frac{V_{t e s t}}{b d}$ & $m$ & $k$ \\
\hline \multirow{2}{*}{5} & A & 47.10 & 305 & 410 & 641 & 151 & 0.0051 & 1.02 & \multirow{4}{*}{164.88} & \multirow{4}{*}{0.11} \\
\hline & $\mathrm{B}$ & 40.84 & 305 & 410 & 641 & 151 & 0.0051 & 0.89 & & \\
\hline \multirow{2}{*}{9} & A & 9.76 & 305 & 1320 & 641 & 87 & 0.0016 & 0.37 & & \\
\hline & B & 10.13 & 305 & 1320 & 641 & 87 & 0.0016 & 0.38 & & \\
\hline \multirow{2}{*}{10} & A & 15.33 & 305 & 710 & 352 & 135 & 0.0016 & 0.37 & \multirow{4}{*}{213.52} & \multirow{4}{*}{0.01} \\
\hline & B & 14.10 & 305 & 710 & 352 & 135 & 0.0016 & 0.34 & & \\
\hline \multirow{2}{*}{11} & A & 5.89 & 305 & 970 & 352 & 72 & 0.0012 & 0.27 & & \\
\hline & B & 5.65 & 305 & 970 & 352 & 72 & 0.0012 & 0.26 & & \\
\hline
\end{tabular}

Table 5. Ultimate loads for the slabs calculated by the PSC method using Eqn (25) and the $m-k$ method using Eqn (2) as well as their comparisons with the elemental and full size test data

\begin{tabular}{|c|c|c|c|c|c|c|c|c|c|c|}
\hline \multicolumn{2}{|c|}{$\begin{array}{c}\text { Specimen \# } \\
\text { (see note) }\end{array}$} & \multirow{2}{*}{$\begin{array}{c}\begin{array}{c}\text { Test \# } \\
\text { (see } \\
\text { note) }\end{array} \\
\text { A }\end{array}$} & \multirow{2}{*}{$\begin{array}{l}\text { Ult. load by the } \\
\text { improved PSC method, } \\
W_{\mathrm{u}, \mathrm{PSC}}\left(\mathrm{kN} / \mathrm{m}^{2}\right) \\
56\end{array}$} & \multirow{2}{*}{$\begin{array}{c}\text { Ult. load by } \\
m-k \text { method, } \\
W_{\mathrm{u}, \mathrm{m}-\mathrm{k}}\left(\mathrm{kN} / \mathrm{m}^{2}\right) \\
64\end{array}$} & \multirow{2}{*}{$\begin{array}{c}\begin{array}{c}\text { Ult. load from } \\
\text { elemental test, } \\
W_{\mathrm{u}, \mathrm{s}}\left(\mathrm{kN} / \mathrm{m}^{2}\right)\end{array} \\
67\end{array}$} & \multirow{2}{*}{$\begin{array}{l}\text { Ult. load from } \\
\text { full size test, } \\
\frac{W_{\mathrm{u}, \mathrm{f}}\left(\mathrm{kN} / \mathrm{m}^{2}\right)}{80}\end{array}$} & \multirow{2}{*}{$\begin{array}{c}\begin{array}{c}W_{\mathrm{u}, \mathrm{s}} / \\
W_{\mathrm{u}, \mathrm{PSC}}\end{array} \\
1.19\end{array}$} & \multirow{2}{*}{$\begin{array}{c}\begin{array}{c}W_{\mathrm{u}, \mathrm{s}} / \\
W_{\mathrm{u}, \mathrm{m}-\mathrm{k}}\end{array} \\
1.05\end{array}$} & \multirow{2}{*}{$\begin{array}{c}\begin{array}{c}W_{\mathrm{u}, \mathrm{f}}{ }^{\prime} \\
W_{\mathrm{u}, \mathrm{PSC}}\end{array} \\
1.43\end{array}$} & \multirow{2}{*}{$\frac{\begin{array}{c}W_{\mathrm{u}, \mathrm{f}^{\mathrm{l}}} \\
W_{\mathrm{u}, \mathrm{m}-\mathrm{k}}\end{array}}{1.26}$} \\
\hline 1 & 21 & & & & & & & & & \\
\hline & & $\mathrm{B}$ & 56 & 64 & 66 & 79 & 1.17 & 1.03 & 1.41 & 1.24 \\
\hline \multirow[t]{2}{*}{2} & 22 & $\mathrm{~A}$ & 23 & 21 & 24 & 20 & 1.05 & 1.18 & 0.87 & 0.97 \\
\hline & & $\mathrm{B}$ & 23 & 21 & 20 & 22 & 0.85 & 0.95 & 0.93 & 1.04 \\
\hline \multirow[t]{2}{*}{3} & 23 & A & 69 & 76 & 71 & 86 & 1.03 & 0.94 & 1.24 & 1.13 \\
\hline & & B & 69 & 76 & 75 & 88 & 1.09 & 0.99 & 1.28 & 1.16 \\
\hline \multirow[t]{2}{*}{4} & 24 & A & 20 & 20 & 20 & 19 & 0.99 & 0.98 & 0.94 & 0.93 \\
\hline & & $\mathrm{B}$ & 20 & 20 & 20 & 19 & 1.01 & 1.00 & 0.94 & 0.93 \\
\hline \multirow[t]{2}{*}{5} & 25 & $\mathrm{~A}$ & 352 & 341 & 487 & - & 1.38 & 1.43 & - & - \\
\hline & & B & 352 & 341 & 422 & - & 1.20 & 1.24 & - & - \\
\hline \multirow[t]{2}{*}{6} & 27 & A & 86 & 88 & 101 & 102 & 1.17 & 1.14 & 1.19 & 1.16 \\
\hline & & B & 86 & 88 & 103 & 107 & 1.20 & 1.18 & 1.24 & 1.21 \\
\hline \multirow[t]{2}{*}{7} & 28 & $\mathrm{~A}$ & 58 & 58 & 65 & - & 1.12 & 1.11 & - & - \\
\hline & & $\mathrm{B}$ & 58 & 58 & 57 & - & 0.98 & 0.98 & - & - \\
\hline \multirow[t]{2}{*}{8} & 29 & $\mathrm{~A}$ & 29 & 25 & 29 & - & 1.00 & 1.19 & - & - \\
\hline & & $\mathrm{B}$ & 29 & 25 & 29 & - & 1.00 & 1.19 & - & - \\
\hline \multirow[t]{2}{*}{9} & 30 & $\mathrm{~A}$ & 22 & 19 & 21 & 18 & 0.95 & 1.07 & 0.84 & 0.94 \\
\hline & & B & 22 & 19 & 21 & 20 & 0.97 & 1.09 & 0.90 & 1.02 \\
\hline \multirow[t]{2}{*}{10} & 31 & $\mathrm{~A}$ & 66 & 63 & 77 & 74 & 1.17 & 1.21 & 1.12 & 1.17 \\
\hline & & B & 66 & 63 & 71 & 70 & 1.08 & 1.12 & 1.07 & 1.11 \\
\hline \multirow[t]{2}{*}{11} & 32 & $\mathrm{~A}$ & 21 & 20 & 23 & 22 & 1.08 & 1.13 & 1.03 & 1.09 \\
\hline & & $\mathrm{B}$ & 21 & 20 & 22 & 23 & 1.03 & 1.09 & 1.08 & 1.13 \\
\hline \multirow[t]{2}{*}{12} & 33 & $\mathrm{~A}$ & 88 & 83 & 88 & 93 & 0.99 & 1.06 & 1.05 & 1.12 \\
\hline & & $\mathrm{B}$ & 88 & 83 & 93 & 86 & 1.06 & 1.13 & 0.97 & 1.04 \\
\hline \multirow[t]{2}{*}{13} & 34 & A & 20 & 17 & 22 & 21 & 1.08 & 1.23 & 1.03 & 1.18 \\
\hline & & B & 20 & 17 & 22 & 23 & 1.08 & 1.23 & 1.13 & 1.29 \\
\hline \multirow[t]{2}{*}{14} & 35 & $\mathrm{~A}$ & 110 & 103 & 125 & 89 & 1.14 & 1.22 & 0.81 & 0.87 \\
\hline & & B & 110 & 103 & 114 & 114 & 1.04 & 1.11 & 1.03 & 1.11 \\
\hline \multirow[t]{4}{*}{15} & 36 & A & 21 & 18 & 23 & 23 & 1.09 & 1.24 & 1.12 & 1.26 \\
\hline & & B & 21 & 18 & 24 & 23 & 1.16 & 1.32 & 1.09 & 1.24 \\
\hline & & & & & & Mean & 1.08 & 1.13 & 1.07 & 1.11 \\
\hline & & & & & & ndard deviation & 0.10 & 0.11 & 0.17 & 0.12 \\
\hline
\end{tabular}

Note: Specimen \# stated under the first heading are as reported in Abdullah and Easterling (2009), and those under the second heading are as reported in Abdullah and Easterling (2007). 


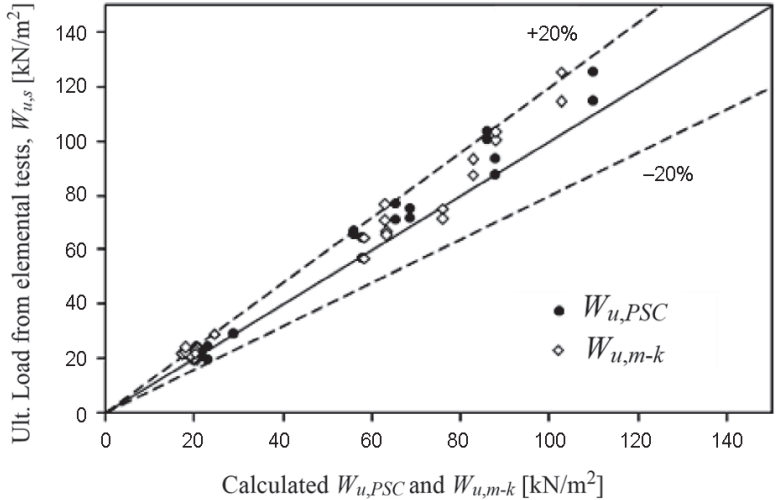

Fig. 11. Comparison of ultimate loads produced from the elemental tests and the calculated loads, using the improved PSC and $m-k$ methods (data from Table 5)

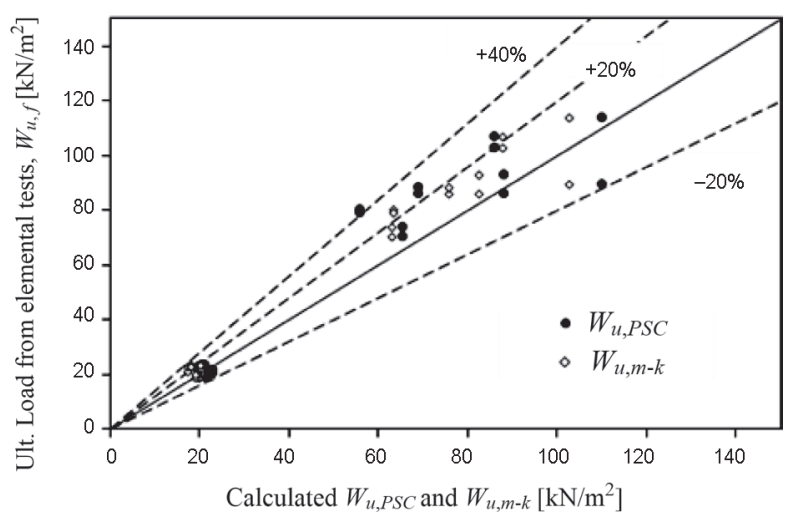

Fig. 12. Comparison of ultimate loads produced from the full size tests and the calculated loads, using the improved PSC and $m-k$ methods (data from Table 5)

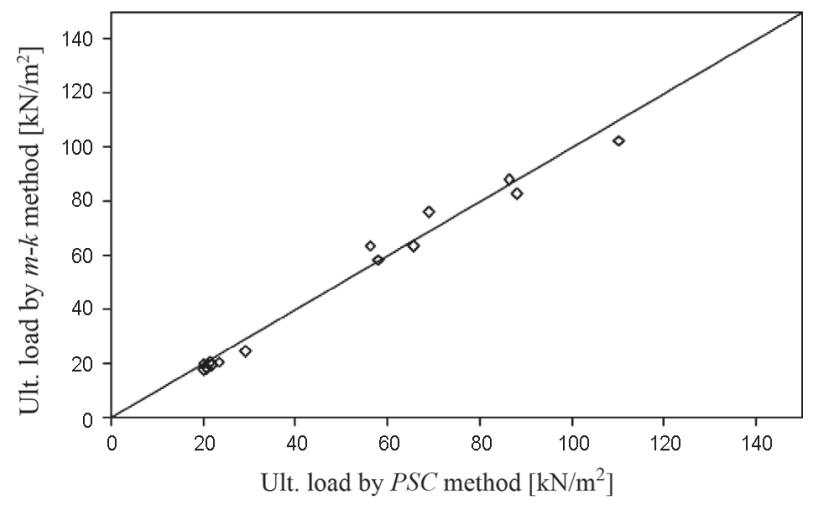

Fig. 13. Comparison of ultimate loads calculated using the $m-k$ and the improved PSC method

\section{Conclusions}

The PSC method for assessing the composite slab strength given in the current Eurocode 4 specifications is highly conservative and less accurate compared to the $m-k$ method. This is attributed to the neglect of the slenderness of the slab in the PSC method. A new equation that relates the shear bond strength and the slab slenderness is therefore proposed in the present study, its validity of which is verified using the bending test data and finite element analysis results. In general, the following conclusions can be drawn from the study:
1. The shear bond-slenderness equation shows that the maximum shear bond stress parameter varies linearly with that of the slenderness of slab. In general, the maximum shear bond stress for compact slabs is larger than that of slender slabs.

2. Because the slenderness effect is introduced into the present PSC method using the shear bondslenderness equation in a similar manner as that of the $m-k$ method, the design of slabs using the improved PSC method can be as accurate.

3. The shear bond-slenderness equation contains the steel deck (sheeting) thickness as its parameter and the bending test data fits considerably well with this equation. In the presence of the sheeting thickness term in the proposed equation, the required number of bending tests to be used in this procedure can be greatly reduced so that no additional test is needed for designing slabs that are built on the same deck profile but with the sheeting thickness different from the test specimen.

4. In order to use the PSC method with the shear bond stress obtained from the proposed shear bond-slenderness equation, the bending test should be conducted for two configurations, namely slender (high $L_{S} / d$ ) and compact (low $L_{S} / d$ ) configurations, similar to the test requirements used for the $m-k$ method.

\section{References}

Abdinasir, Y.; Abdullah, R.; Mustaffa, M. 2012. Modelling of shear bond with cohesive element and slenderness study of composite slabs, in Proceedings of Joint Conference of the $8^{\text {th }}$ Asia Pacific Structural Engineering \& Construction Conference (APSEC) and $1^{\text {st }}$ International Conference on Civil Engineering Conference (ICCER), APSEC-ICCER 2012, 4-2 October 2012, Surabaya, Indonesia, 208-216.

Abdullah, R.; Easterling, W. S. 2007. Determination of composite slab strength using a new elemental test method, Journal of Structural Engineering 133(9): 1268-1277. http://dx.doi.org/10.1061/(ASCE)07339445(2007)133:9(1268)

Abdullah, R.; Easterling, W. S. 2009. New modeling and evaluation procedures for horizontal shear bond in composite slabs, Journal of Constructional Steel Research 65(4): 891-899. http://dx.doi.org/10.1016/j.jcsr.2008.10.009

Abdullah, R.; Paton-Cole, V. P.; Easterling, W. S. 2007. Quasistatic analysis of composite slab, Malaysian Journal of Civil Engineering 19(2): 91-103.

ANSI/AASCE 3-91. 1992. ASCE Standard for the Structural Design of Composite Slabs. New York: American Society of Civil Engineers.

Bode, H.; Dauwel, T. 1999. Steel-concrete composite slabs - design based on partial connection, in Proceedings of the International Conference on Steel and Composite Structures, 24-25 February 1999, Delft, The Netherlands, 2.1-2.10.

Bode, H.; Minas, F.; Sauerborn, I. 1996. Partial connection design of composite slabs, Structural Engineering International 6(1): 53-56. http://dx.doi.org/10.2749/101686696780496021

Bode, H.; Sauerborn, I. 1992. Modern design concept for composite slabs with ductile behaviour, in Proceedings of an Engineering Foundation Conference on Composite Construction in Steel and Concrete II. American Society of Civil Engineers, 14-19 June 1992, Trout Lodge, Potosi, Missouri, 125-141. 
Calixto, J. M.; Lavall, A. C.; Melo, C. B.; Pimenta, R. J.; Monteiro, R. C. 1998. Behaviour and strength of composite slabs with ribbed decking, Journal of Constructional Steel Research 46(1): 211-212. http://dx.doi.org/10.1016/S0143-974X(98)00127-8

Chen, S.; Shi, X. 2011. Shear bond mechanism of composite slabs - a universal FE approach, Journal of Constructional Steel Research 67(10): 1475-1484. http://dx.doi.org/10.1016/j.jcsr.2011.03.021

Crisinel, M.; Marimon, F. 2004. A new simplified method for the design of composite slabs, Journal of Constructional Steel Research 60(3-5): 481-491. http://dx.doi.org/10.1016/S0143-974X(03)00125-1

CSSBI 12M - 96. 1996. CSSBI Standard for Composite Steel Deck. Canadian Sheet Steel Building Institute.

Daniels, B. J. 1988. Shear bond pull-out tests for cold-formedsteel composite slabs. ICOM 194 - Construction Metallique, Department de Genie Civil, Ecole Polytechnique Federale de Lausanne.

Daniels, B. J.; Crisinel, M. 1993. Composite slab behavior and strength analysis. Part I: calculation procedure, Journal of Structural Engineering 119(1): 16-35.

http://dx.doi.org/10.1061/(ASCE)0733-9445(1993)119:1(16)

EN1994-1.1. 2004. Eurocode 4: Design of Composite Steel and Concrete Structures - Part 1.1: General Rule and Rules for Buildings. Brussels: European Committee for Standardization.

Ferrer, M.; Marimon, F.; Crisinel, M. 2006. Designing coldformed steel sheets for composite slabs: an experimentally validated FEM approach to slip failure mechanics, Thin Walled Structures 44(12): 1261-1271. http://dx.doi.org/10.1016/j.tws.2007.01.010

Jeong, Y. J.; Kim, H. Y.; Koo, H. B. 2009. Longitudinal shear resistance of steel-concrete composite slabs with perfobond shear connectors, Journal of Constructional Steel Research 65(1): 81-88.

http://dx.doi.org/10.1016/j.jcsr.2008.01.031

Johnson, R. P. 1994. Composite structures of steel and concrete, Vol. 1: Beams, Slabs, Columns, and Frames for Buildings. Oxford: Blackwell Scientific Publication, 43-44.

Kim, H. Y.; Jeong, Y. J. 2010. Ultimate strength of a steel concrete composite bridge deck slab with profiled sheeting, Engineering Structures 32(2): 534-546. http://dx.doi.org/10.1016/j.engstruct.2009.10.014

Luttrell, L. D. 1987. Flexural strength of composite slabs, in R. Narayanan (Ed.). Composite steel structures - advances, design and construction. London: Elsevier, 106-115.

Mohammed, B. S. 2010. Structural behavior and $m-k$ value of composite slab utilizing concrete containing crumb rubber, Construction and Building Materials 24(7): 1214-1221. http://dx.doi.org/10.1016/j.conbuildmat.2009.12.018
Mohammed, B. S.; Al-Ganad, M. A.; Abdullahi, M. 2011. Analytical and experimental studies on composite slabs utilising palm oil clinker concrete, Construction and Building Materials 25(8): 3550-3560. http://dx.doi.org/10.1016/j.conbuildmat.2011.03.048

Patrick, M.; Bridge, R. Q. 1994. Partial shear connection design of composite slabs, Engineering Structures 16(5): 348-362. http://dx.doi.org/10.1016/0141-0296(94)90028-0

Schuster, R. M. 1970. Strength and behavior of cold-rolled steeldeck-reinforced concrete floor slabs. PhD Dissertation. Iowa State University, Ames, Iowa, USA.

Seleim, S. S.; Schuster, R. M. 1985. Shear-bond resistance of composite deck-slabs, Canadian Journal of Civil Engineering 12(2): 316-324. http://dx.doi.org/10.1139/185-034

Seres, N. 2012. Behaviour and resistance of concrete encased embossments in composite floors. $\mathrm{PhD}$ Dissertation. Budapest University of Technology and Economics, Hungary.

Stark, J. W. B. 1978. Design of composite floors with profiled steel sheet, in Proceedings of the $4^{\text {th }}$ International Specialty Conference on Cold-Formed Steel Structures, 1-2 June 1978, St. Louis Missouri-Rolla, 893-992.

Stark, J. W. B.; Brekelmans, J. W. P. M. 1990. Plastic design of continuous composite slabs, Structural Engineering International 6(1): 47-53.

http://dx.doi.org/10.2749/101686696780495914

Tsalkatidis, T.; Avdelas, A. 2010. The unilateral contact problem in composite slabs: experimental study and numerical treatment, Journal of Constructional Steel Research 66(3): 480-486. http://dx.doi.org/10.1016/j.jcsr.2009.10.012

Tzaros, K. A.; Mistakidis, E. S.; Perdikaris, P. C. 2010. A numerical model based on nonconvex-nonsmooth optimization for the simulation of bending tests on composite slabs with profiled steel sheeting, Engineering Structures 32(3): 843-853. http://dx.doi.org/10.1016/j.engstruct.2009.12.010

Valivonis, J. 2006. Analysis of behaviour of contact between the profiled steel sheeting and the concrete, Journal of Civil Engineering and Management 12(3): 187-194. http://dx.doi.org/10.1080/13923730.2006.9636392

Veljkovic, M. 1995. Longitudinal shear capacity of composite slabs, in Proceedings of Nordic Steel Construction Conference, 19-21 June 1995, Malmo, Sweden, 547-554.

Veljkovic, M. 1996. An improved partial connection method for composite slab design, in Proceedings of an Engineering Foundation Conference in Composite Construction in Steel and Concrete III, American Society of Civil Engineers, 9-14 June 1996, Irsee, Germany, 644-659.

Widjaja, B. R.; Easterling, W. S. 1996. Strength and stiffness calculation procedures for composite slabs, in Proceedings of the $13^{\text {th }}$ International Specialty Conference on Cold-Formed Steel Structures, 17-18 October 1996, St. Louis, Missouri, 389-401.

Redzuan ABDULLAH. PhD, Associate Professor, Faculty of Civil Engineering, Universiti Teknologi Malaysia. Research interests: Finite element modeling and application, composite slab behavior, experimental research.

\begin{abstract}
Ahmad Beng Hong KUEH. PhD, Senior Lecturer and Research Fellow, Construction Research Centre, Universiti Teknologi Malaysia (UTM-CRC). Research interests: Fibrous composite thermo-mechanics, bio-inspired structures and materials, structural and material dynamic characteristics, electro-magnet-thermo-mechanics of biosolids and biofluids, steel connection mechanics.
\end{abstract}

Izni Syahrizal IBRAHIM. PhD, Senior Lecturer, Faculty of Civil Engineering, Universiti Teknologi Malaysia. Research interests: Precast concretes design and construction, composite action in structure, fiber reinforced concrete and application of waste materials in civil engineering.

W. Samuel EASTERLING. PhD, Professor and Department Head, The Charles E. Via, Jr. Department of Civil and Environmental Engineering, Virginia Tech. Research interests: Steel-concrete composite structures, steel structures, cold-formed steel structures, partially-restrained connections, experimental research. 